\title{
A experimentação como território: o legado indisciplinar de John Cage
}

\author{
Experimentation as a territory: the indisciplinary \\ legacy of John Cage
}

Karina Campos de Almeida ${ }^{1}$

Lidia Olinto ${ }^{2}$ 


\section{Resumo}

Este artigo apresenta e analisa 0 legado prático-teórico do compositor John Cage com o objetivo de discutir como sua obra problematizava as convenções artísticas até então tácitas e borrava as fronteiras entre as diversas formas de expressão artística, sendo, por isso, não apenas transdisciplinar como, acima de tudo, indisciplinar. Exploramos também como as proposições cageanas reverberaram no trabalho de alguns artistas como Childs, Rainer, Brown - dentre outros - influenciando muitas experimentações dos anos cinquenta e sessenta (contexto norte-americano) que operaram uma profunda mudança paradigmática em todos os campos artísticos, com especial destaque para as Artes Cênicas.

Palavras-chave: John Cage; composição; artes cênicas; dança; transdisciplinaridade.

\section{Abstract}

This article analyzes the practical-theoretical legacy of the composer John Cage. The objective is to point out how his work problematized the artistic conventions and blurred the boundaries between different artistic expression forms. Because of this, his legacy is not only transdisciplinary but above all indisciplinary. We also explore how Cage's propositions reverberated in the work of some artists such as Childs, Rainer, Brown, among others. During the fifties and sixties (North American context) these artists' experiments operated a profound paradigmatic change in all artistic fields, especially the Performing Arts.

Keywords: John Cage; composition; performing arts; dance; transdisciplinarity.

ISSN: 1414.5731

E-ISSN: 2358.6958

1 Dra. em Artes da Cena pela UNICAMP. Dançarina, coreógrafa e professora de dança contemporânea. kadanca@gmail.com

2 Dra. em Artes da Cena pela UNICAMP. Atriz/performer/dançarina, diretora, produtora e dramaturga em processos colaborativos. lidiaolinto@gmail.com 
Ao longo de sua trajetória, John Cage $^{3}$ (1912-1992) transitou entre diversos campos do conhecimento - Música, Poesia, Filosofia e Artes Visuais - através de suas obras, atos performativos, aulas e palestras. Suas ações carregavam um investimento simbólico 4 e causavam deslocamentos daquilo que era dado como padrão/modelo nas esferas socioculturais, fazendo com que Cage passasse a ocupar um lugar importante na História da Arte do século XX. Questionando o que seria o ato criador e suas implicações, Cage desenvolveu distintas maneiras de abordar a composição musical. Suas propostas e estratégias compositivas não só romperam com as convenções musicais, como também atravessaram os limites do campo da música, levando a sua ideia de "composição experimental" a outras formas de expressão artística.

Enquanto esteve na Cornish School, em Seattle (entre 1938 e 1942), trabalhando como músico nas aulas de dança moderna da coreógrafa Bonnie Bird, Cage começou a trabalhar com as estruturas rítmicas de um modo não tradicional, criando um grupo de percussão e desenvolvendo investigações que se diferenciavam das convenções estabelecidas em termos de música e de instrumentação. Nesse período, Cage realizou a sua primeira conferência intitulada "The Future of Music: Credo". É dessa conferência uma de suas falas mais citadas: "Se essa palavra 'música' é sagrada e reservada para instrumentos dos séculos XVIII e XIX, nós podemos substituí-la por um termo mais significativo: organização do som" (Cage, 1961, p.3) ${ }^{5}$. Se, para Cage, a música passa a ser a organização do som, a denominação "compositor" passa a ser sinônimo de inventor, isto é, alguém que cria não só novas músicas, mas também novos sons e instrumentos. Nesse sentido, as proposições de Cage revelam a sua necessidade de inventar outros modos e métodos de composição e de repensar a própria Música.

Dentre as invenções cageanas, exploraremos neste artigo a criação do piano preparado, as operações do acaso, o seu trabalho com as noções de partitura e de silêncio, com intuito de demonstrar como seu legado foi não apenas transdisciplinar, mas principalmente, indisciplinar, isto é, estimulador da ruptura com o status quo, sendo até hoje uma grande referência para todos aqueles interessados na prática da composição nas diversas áreas artísticas, incluindo as Artes da Cena.

\section{Como o piano veio a ser preparado}

No início dos anos de 1940, dando continuidade as suas investigações, Cage iniciou as experimentações sobre o que veio a ser conhecido como piano preparado. Em seu texto How the Piano Came to be Prepared (1981), Cage diz que três ou quatro dias antes da estreia, Sylvilla Fort o convidou para compor uma música para seu trabalho intitulado Bacchanal. Cage aceitou o convite e começou a pensar em duas

\footnotetext{
${ }^{3}$ John Cage (1912-1992), músico, compositor, escritor e filósofo estadunidense cujas proposições experimentais marcaram o século XX. Foi aluno de Henry Cowell (1897-1965) e Arnold Schoenberg (1874-1951), reconhecidos por suas inovações radicais no campo da música. As obras de Cage também foram influenciadas pelo Zen Budismo, I-Ching e pela filosofia indiana, especialmente pelos ensinamentos de Daisetsu Teitaro Suzuki (1870-1966) e Ananda Coomaraswamy (1877-1947). Cage foi parceiro de Merce Cunningham (1919-2009), deixando um grande legado que inspirou diversos artistas das artes da cena, por exemplo, aqueles que formaram o coletivo Judson Dance Theater.

${ }^{4}$ Em John Cage y la "investidura": emascular o sistema, Robinson (2009) discute o que denomina de modelo estratégico de "investimento simbólico" de Cage a partir da noção de "investimento" do historiador Eric Santner.

5 "If this word 'music' is sacred and reserved for eighteenth- and nineteenth-century instruments, we can substitute a more meaningful term: organization of sound" (Cage, 1961, p.3 - Tradução nossa).
} 
possibilidades de composição: a primeira seria uma música dodecafônica para piano ou orquestra, e a segunda uma peça para conjuntos de percussão para três, quatro ou seis músicos. Porém, o espaço do teatro da Cornish School em que Fort iria se apresentar era muito pequeno e não comportaria a quantidade de músicos e instrumentos pensados inicialmente por Cage. Na parte da frente do palco, havia um piano e, embora a ideia de utilizar um conjunto de percussão parecesse mais adequada ao tema da coreografia de Fort, Cage se viu obrigado a mudar as suas ideias iniciais e, então, compôs uma música para piano (Cage, 1981). Buscando alterar o som do piano de modo que ele produzisse uma música adequada para o trabalho de Fort, Cage descreveu os procedimentos criativos que experimentou:

Fui para a cozinha, peguei um prato de torta, trouxe de volta para a sala e coloquei-o sobre as cordas de piano. Toquei algumas teclas. Os sons do piano foram modificados, mas o prato de torta quicou devido às vibrações e, depois de um tempo, alguns dos sons que tinham sido alterados já não eram mais. Eu experimentei algo menor, pregos entre as cordas. Eles deslizaram para baixo, entre e longitudinalmente ao longo das cordas. Ocorreu-me que parafuso ou porcas ficariam na posição. Eles ficaram. E fiquei muito feliz por notar que, por meio de uma única preparação, dois sons diferentes poderiam ser produzidos. Um era ressonante, o outro era silencioso e mudo. O silencioso era ouvido sempre que o pedal macio era utilizado. Eu escrevi o Bacchanal de forma rápida e com o entusiasmo contínuo dado pela descoberta (Cage, 1981, p.7-8) .

As próximas composições de Cage para piano preparado foram criadas a partir de 1942, quando Cage se mudou para Nova York, sendo o seu primeiro concerto realizado em 1943, no Museu de Arte Moderna (MoMA). Em 1944, Cage e Merce Cunningham iniciaram seus trabalhos em parceria. Conforme aponta Robinson (2009), a década de 1940 em Nova York foi um período turbulento para Cage, tanto na vida pessoal, como na carreira artística. Um período de luz e sombras, que não só envolveu uma luta em consolidar a sua reputação emergente, mas também entender a sua posição marginal dentro de uma sociedade opressivamente heteronormativa. Cage estava se divorciando de sua esposa, Xenia, que também era musicista, e iniciando a sua relação amorosa com Merce Cunningham (1919-2009). Ao assumir um modo de vida contrastante com a sociedade patriarcal norte-americana dos anos quarenta, Cage necessariamente teve que compreender que sua decisão afetaria seus constantes esforços para organizar a sua vida profissional nesse contexto. $E$, de acordo com Robinson (2009), essa questão, sem dúvida, teve um significado complexo para a compreensão do lugar que ocupou Cage em sua geração, que em vários âmbitos envolveu um modo de pensar e agir fora das convenções socioculturais estabelecidas.

Nesse período, Cage continuou trabalhando nas composições para piano preparado e, dentre outras obras, The Perilous Night (1944) causou grande repercussão. As instruções encontradas na partitura de The Perilous Night revelam como as indicações de Cage acerca dos materiais a serem utilizados, bem como a definição de

\footnotetext{
6 "I went to the kitchen, got a pie plate, brought it back into the living room, and placed it on the piano strings. I played a few keys. The piano sounds had been changed, but the pie plate bounced around due to the vibrations, and, after a while, some of the sounds that had been changed no longer were. I tried something smaller, nails between the strings. They slipped down between and lengthwise along the strings. It dawned on me that screw or bolts would stay in position. They did. And I was delighted to notice that by means of a single preparation two different sounds could be produced. One was resonant, the other was quiet and muted. The quiet one was heard whenever the soft pedal was used. I wrote the Bacchanal quickly and with the excitement continual discovery provided". (Cage, 1981, p.7-8 - Tradução nossa).
} 
seu posicionamento, tornaram-se, ao longo do tempo, cada vez mais precisas. Essas especificações, que eram provenientes de sua prática de constante experimentação com diversos materiais que pudessem produzir diferentes sons, revelam o emprego de estratégias composicionais consistentes que podem ser identificadas em toda a trajetória de Cage.

Cage nos diz que suas ideias sobre o que poderia ser o piano preparado surgiram através do contato com trabalhos de seus amigos artistas, do seu estudo sobre o Zen Budismo, suas divagações pelos campos e florestas e todo tipo de experiência que lhe permitia aproveitar as coisas como elas são e como elas acontecem (Cage, 1981). Cage também comenta que outros compositores fizeram uso do piano preparado e que tal prática de experimentação passou a ter vida própria:

Quando posicionei objetos entre as cordas do piano pela primeira vez, era o desejo de possuir sons (ser capaz de repeti-los). Mas, à medida que a música deixou minha casa e passou de piano para piano e de pianista para pianista, ficou claro que não apenas dois pianistas são essencialmente diferentes um do outro, mas dois pianos também não são os mesmos. Em vez da possibilidade de repetição, nos deparamos na vida com as qualidades únicas e características de cada ocasião $^{7}$ (Cage, 1981, p.07-08. Grifo nosso).

Cage, então, passa a considerar a imprevisibilidade e a indeterminação na performance. Ainda que haja uma partitura, a performance se evidencia como um evento singular, no qual a repetição é entendida como a manifestação das transformações de um fenômeno que é, e sempre será, único.

\section{Operações do acaso}

A partir dos anos de 1950, desdobrando as ideias que surgiram com a criação do piano preparado, no qual cada tecla do instrumento era programada para ter um som próprio, Cage passou a criar composições instrumentais a partir da combinação limitada de uma coleção de harmonias e sonoridades. É desse período a obra Sixteen Dances for Soloist and Company of Three (1951), criada em parceria com Cunningham, envolvendo a utilização de operações de acaso tanto na composição da música como das coreografias.

Sixteen Dances marca um ponto de transição na carreira de Cage, um passo significativo no desenvolvimento de técnicas que utilizavam possibilidades sonoras predeterminadas (chamadas por ele de sound gamuts). Para a composição dessa peça, Cage elaborou uma série de tabelas que permitiam a combinação aleatória de inúmeras estruturas rítmicas. Nesse mesmo período, o compositor Christian Wolf apresentou para Cage o livro I-Ching, The book of Changes. Cage imediatamente relacionou as tabelas que utilizava com as tabelas usadas para identificar os hexagramas chineses e percebeu que esse livro poderia ser uma interessante referência para as operações do acaso que ele já investigava. Além de Sixteen Dances, Music of Changes

\footnotetext{
7 "When I first placed objects between piano strings, it was the desire to possess sounds (to be able to repeat them). But, as the music left my home and went from piano to piano and from pianist to pianist, it became clear that not only two pianists essentially different from one another, but two pianos are not the same either. Instead of the possibility of repetition, we are faced in life with the unique qualities and characteristics of each occasion" (Cage, 1981, p.07-08 - Tradução nossa).
} 
e Imaginary Landscape No. 4 são outros exemplos de peças criadas ao longo do ano de 1951 que também utilizavam operações do acaso (Pritchett, 2009).

Em Sixteen Dances, o procedimento de utilização do acaso nas composições permitia que tanto Cage quanto Cunningham se deparassem com possibilidades sonoras e coreográficas que iam além de suas escolhas pessoais. Nessa obra, o processo de composição da música era o movimento de um lugar da tabela para outro, a organização rítmica em frases de um som após o outro. Cage percorria as células da tabela fazendo movimentos arbitrários ao longo de suas linhas, colunas e diagonais, o que promovia o surgimento de uma ampla variedade sonora e a criação de continuidades inesperadas para os sons. Cada um dos sons poderia ser considerado interessante por si só e também poderiam ser combinados de maneiras ilimitadas com as demais possibilidades sonoras (Pritchett, 2009). Acerca de sua parceria com Cunningham, Cage disse:

A partir dessa independência de música e dança, um ritmo resulta, o qual não é o dos cascos dos cavalos ou de outras batidas regulares, mas o que nos lembra de uma multiplicidade de eventos no tempo e no espaço. [...] Nós não estamos, nessas danças e música, dizendo alguma coisa. Somos ingênuos o suficiente para pensar que se estivéssemos dizendo algo nós usaríamos palavras. Ao invés disso, estamos fazendo algo. $O$ significado do que fazemos é determinado por cada um que vê e ouve. [...] $\mathrm{O}$ movimento é o movimento do corpo. É aqui que o Sr. Cunningham concentra sua atenção coreográfica e não sobre os músculos faciais. $\mathrm{Na}$ vida cotidiana, as pessoas habitualmente observam rostos e gestos, traduzindo o que veem em termos psicológicos. Aqui, no entanto, estamos em presença de uma dança que utiliza todo o corpo, exigindo para a sua fruição o uso de sua faculdade de simpatia cinestésica. A inovação do nosso trabalho deriva, portanto, de termos nos afastado de preocupações humanas simplesmente privadas e nos aproximado do mundo da natureza e da sociedade da qual todos nós somos uma parte (Cage, 1961, p. 94-95 - Grifos nossos) ${ }^{8}$.

A partir da citação acima, é possível notar aspectos fundamentais sobre a parceria Cage-Cunningham. $O$ investimento que os artistas fizeram na independência entre dança e música inaugurou um novo modo de trabalho colaborativo. A música (e suas características estéticas) deixou de ser a base para a composição coreográfica, e a duração do tempo passa a ser a conexão entre as duas linguagens. E, além disso, não havia uma hierarquia entre uma linguagem e a outra. Cunningham passou a criar suas danças em silêncio, marcando meticulosamente com um cronômetro o tempo de cada frase coreográfica. Cage, então, tomava a duração do tempo como a principal estrutura a ser seguida para a composição musical. Muitas vezes, dança e música eram justapostas apenas na estreia. Cage e Cunningham estavam interessados na multiplicidade de sentidos que poderiam emergir do próprio som e do próprio movimento, distanciando-se de qualquer caráter figurativo ou representacional que pu-

\footnotetext{
8 "From this independence of music and dance a rhythm results which is not that of horses' hoofs or other regular beats but which reminds us of a multiplicity of events in time and space [...] We are not, in these dances and music, saying something. We are simple-minded enough to think that if we were saying something we would use words. We are rather doing something. The meaning of what we do is determined by each one who sees and hears it. [...] The movement is the movement of the body. It is here that Mr. Cunningham focuses his choreographic attention, not on the facial muscles. In daily life people customarily observe faces and hand gestures, translating what they see into psychological terms. Here, however, we are in the presence of a dance which utilizes the entire body, requiring for its enjoyment the use of your faculty of kinesthetic sympathy. The novelty of our work derives therefore from our having moved away from simply private human concerns towards the world of nature and society of which all of us are a part". (Cage, 1961, p. 94-95 - Tradução nossa).

Para um detalhamento sobre a dança moderna e a modernização da dança ver Dando Corpo à História (Cavrell, 2015)
} 
desse construir algum tipo de narrativa linear. Para Cunningham não havia nenhum outro objetivo além da própria dança, no sentido do emprego de algum subtexto que justificasse a escolha deste ou daquele movimento. E o mesmo valia para a música, cenário, iluminação e figurino. Na parceria Cage-Cunningham, quaisquer sentidos ou relações possíveis que pudessem emergir viriam da coexistência entre esses elementos, ou ainda, da colisão, justaposição e interseção entre eles. A independência entre dança e música, o investimento no som "sendo ele mesmo" e no "movimento pelo movimento" abriram caminho para inovadoras formas de criação, que se opunham radicalmente aos pressupostos composicionais e dramáticos que guiavam a dança moderna? .

No início dos anos de 1950, além de consolidar a sua parceria com Cunningham, Cage conheceu Robert Rauschenberg, um dos artistas visuais mais importantes do Expressionismo Abstrato e da Pop Art. O encontro entre Cage, Cunningham e Rauschenberg gerou uma das mais potentes colaborações artísticas do século XX. Como exemplo dessa parceria, podemos citar os Happenings ${ }^{10}$ realizados na Black Mountain College, que contavam com a participação de artistas de diferentes áreas. Em 1952, Cage, Cunningham, Rauschenberg e também o pianista David Tudor e os poetas M.C. Richards e Charles Olson prepararam ações que poderiam ter intersecções umas com as outras, criando a obra Untitled Event (Theater Piece). Rauschenberg pendurou, a partir do teto, algumas de suas White Paintings (1951) e tocou discos de vinil numa antiga vitrola; Cunningham dançou ao redor do público e nos corredores, enquanto um cão lhe seguia; Tudor tocou uma partitura de Cage para piano; Richards e Olson leram poesia e Cage proclamou um de seus textos do alto de uma escada. Em Untitled Event (Theater Piece), Cage explorou pela primeira vez a noção de recepção individualizada através de algumas práticas específicas, tais como a dispersão dos intérpretes e dos alto-falantes ao redor e no meio do público. Esse tipo de distribuição acústica fragmentava o som executado, de modo que cada integrante do público ouvia uma qualidade particular do som, gerando uma multiplicidade de experiências sonoras. Nas palavras de Cage:

Os ensaios têm mostrado que esta nova música, seja para fita ou para os instrumentos, é mais claramente ouvida quando os vários alto-falantes ou performers estão separados no espaço, em vez de agrupados em conjunto. Para isso, a música não está envolvida com uma sonoridade harmônica como geralmente entendida, onde a qualidade da harmonia resulta a partir de uma mistura de vários elementos. Aqui, estamos preocupados com a coexistência do diferente e os pontos centrais onde a fusão ocorre são muitos: os ouvidos dos ouvintes onde quer que estejam. Essa desarmonia, parafraseando a afirmação de Bergson sobre desordem, é simplesmente uma harmonia a que muitos estão desacostumados. [...] E qual é o propósito de escrever música? Um deles é, obviamente, não lidar com propósitos, mas lidar com os sons. Ou a resposta deve assumir a forma de paradoxo: um "sem propósito" proposital ou uma peça sem propósito. Este jogo, no entanto, é uma afirmação de vida - não uma tentativa de trazer a ordem a partir

${ }^{9}$ Para um detalhamento sobre a dança moderna e a modernização da dança ver Dando Corpo à História (Cavrell, 2015).

${ }^{10} \mathrm{O}$ Happening, como conceito de encenação, passou a ser difundido a partir de Allan Kaprow com a sua obra 18 Happenings in 6 parts (1959). 
do caos, nem sugerir melhorias na criação, mas simplesmente uma maneira de acordar para própria vida que estamos vivendo, que é tão excelente, uma vez que alguém tira sua mente e seu desejo do caminho e deixa a vida agir por sua própria harmonia (Cage, 1961, p.12) ${ }^{11}$.

Em suas composições, Cage, então, passa a considerar a música livre de toda mensagem expressiva ou comunicativa no sentido tradicional; o ato de "interpretação" realizado pelo público dá espaço ao que Cage denominava de "capacidade de resposta sensível" ou "capacidade de resposta": uma forma de recepção que surge da execução, mas que não vem determinada por ela; uma recepção que é constitutivamente dependente de cada um dos integrantes do público, tanto como é do compositor e do intérprete (Cage, 1961). Em suas composições, Cage, então, passa a considerar a música livre de toda mensagem expressiva ou comunicativa no sentido tradicional; o ato de "interpretação" realizado pelo público dá espaço ao que Cage denominava de "capacidade de resposta sensível" ou "capacidade de resposta": uma forma de recepção que surge da execução, mas que não vem determinada por ela; uma recepção que é constitutivamente dependente de cada um dos integrantes do público, tanto como é do compositor e do intérprete (Cage, 1961).

Dentro de todo o legado de Cage, o conceito de acaso adquiriu diversos sentidos e inspirou inúmeros artistas. Vale ressaltar que o acaso como conceito operativo não pode ser considerado como uma "invenção" ou singularidade exclusiva de Cage. Sabe-se que o emprego de operações do acaso também foi utilizado anteriormente, por exemplo, pelos dadaístas e pelos surrealistas. E o trabalho de Cage acerca do acaso foi "processado" de inúmeras formas por outros artistas, especialmente aqueles que participaram dos cursos de Composição e de Composição Experimental, ambos ministrados por ele dentro das atividades letivas da New School for Social Research, em Nova York, entre o outono de 1956 e o verão de 1960. Dentre os artistas que foram alunos de Cage estão: Richard Maxfield, Toshi Ichiynagi, Robert Dunn, George Brecht, Jackson Mac Low, Dick Higgins, Allan Kaprow e Al Hansen. Como tarefa das aulas, Cage frequentemente pedia aos alunos para que escrevessem partituras e que trouxessem o material para apresentar na próxima aula. Como a maioria dos alunos não compunha música, eles criavam suas partituras utilizando palavras. Isso marca o começo de um outro modo de olhar para a música, no sentido da expansão da utilização da ideia de partitura e também de outros elementos musicais (Joseph, 2009).

A origem do movimento Fluxus ${ }^{12}$ situa-se em torno dessas aulas de Cage, em

\footnotetext{
11 "Rehearsals have shown that this new music, whether for tape or for instruments, is more clearly heard when the several loud-speakers or performers are separated in space rather than grouped closely together. For this music is not concerned with harmoniousness as generally understood, where the quality of harmony results from a blending of several elements. Here we are concerned with the coexistence of dissimilar, and the central points where fusion occurs are many: the ears of the listeners wherever they are. This disharmony, to paraphrase Bergson's statement about disorder, is simply a harmony to which many are unaccustomed. [...] And what is the purpose of writing music? One is, of course, not dealing with purposes but dealing with sounds. Or the answer must take the form of paradox: a purposeful purposelessness or a purposeless play. This play, however, is an affirmation of life - not an attempt to bring order out of chaos nor to suggest improvements in creation, but simply a way of waking up to the very life we're living, which is so excellent once one gets one's mind and one's desires out of its way and lets it act of its own accord". (Cage, 1961, p. 12 - Tradução nossa)

${ }^{12}$ Fluxus foi um movimento artístico internacional e interdisciplinar de vanguarda, atuante entre 1960 e 1970 nos Estados Unidos e a Europa. Os artistas engajavam-se em ações experimentais manifestadas através da música, poesia, artes visuais, performances, instalações, happenings, dentre outras proposições inovadoras para a época. Sua origem está ligada a figura de George Maciunas (1931-1978), responsável pela publicação de uma revista nomeada Fluxus e do Festival Internacional de Música Nova, em Wiesbaden, Alemanha, em 1962. As proposições de Marcel Duchamp associadas ao ready-made e as ações experimentais de John Cage exerceram grande influência nas proposições dos artistas do Fluxus. O loft da artista Yoko Ono, em Nova York, também foi fundamental para a gestação do movimento, abrigando diversas reuniões e performances. Fizeram parte do Fluxus os artistas: George Maciunas, La Monte Young, George Brecht, Al Hansen, Scott Hyde, Allan Kaprow, Joseph Beuys, Yoko Ono, Dick Higgins, Jackson Mac Low, Alison Knowles, Nam June Paik, dentre outros. Ver: Arte hoy - Fluxus (Estella, 2012).
} 
que os alunos tinham a oportunidade de realizar experimentações autodirigidas. Mesmo que cada artista tenha seguido seus caminhos particulares, é possível identificar em seus percursos conceitos nitidamente cageanos. Dentre eles, pode-se citar, por exemplo, a noção cageana de "ações experimentais", desdobradas tanto por Hansen quanto por Kaprow, como forma de buscar e dialogar com o imprevisível. E, para Cage, "[...] a palavra 'experimental' é apropriada, desde que seja entendida não como descritivo de um ato a ser julgado em termos de sucesso e fracasso, mas simplesmente como de um ato cujo resultado é desconhecido" (Cage, 1955, p.13) ${ }^{13}$.

Nos anos de 1950, Cage levou a sua ideia de experimentação para a criação de um tipo particular de notação musical que não mais necessariamente apresentava notas musicais em suas pautas. Essas partituras apresentavam desenhos, indicações gráficas, como pontos ou linhas e, também, números e palavras. O método de desenho por pontos é um exemplo dessa experimentação realizada por Cage, que utiliza o acaso no momento da composição de partituras. Nesse método, Cage anotava pontos em uma folha de papel marcando, por exemplo, um determinado número de imperfeições encontradas na própria folha, ou dobrando o papel para, depois, obter os pontos através de furos feitos nas intersecções das dobras. Depois desse processo, Cage desenhava pautas musicais no papel e transformava os pontos em notas. Para Cage, esse método permitia que certos aspectos do som fossem determinados como se o som estivesse em um campo acústico e tomasse formas independentes das preconcepções do compositor.

As partituras criadas por Cage baseadas no acaso e na aleatoriedade podem ser vistas como "quebra-cabeças compositivos" em que as "respostas" ou "soluções" (como, por exemplo, o modo de execução das notas) são variáveis, ilimitadas e, sobretudo, desconhecidas tanto para o compositor como para o intérprete. Para o compositor, a situação consistia em acessar um território sonoro sem precedentes, já o intérprete se deparava com uma partitura elaborada de um modo menos convencional e que exigiria dele um tipo de engajamento mais aberto e criativo.

\section{4'33'"14 e o Silêncio}

Considerada um marco nas investigações de Cage sobre o silêncio, 4'33" (1952) é um exemplo de obra que apresenta em sua partitura instruções dadas ao performer através de palavras e imagens ${ }^{15}$. Em 4'33" a partitura "age" ao "dizer" ao performer para permanecer em silêncio durante os três movimentos que constituem a peça. Tal partitura manifesta-se como um ato performativo, atrelado ao caráter pragmático da experiência, onde o performer se coloca em silêncio, convocando, por meio da sua própria ação, a atenção dos espectadores para o ambiente e para si mesmos. A partitura age como um dispositivo poético, direcionando a escuta dos espectadores para os mais variados sons que compõem o tempo e espaço em questão: o som das

\footnotetext{
13 “' [...] the word 'experimental' is apt, providing it is understood not as descriptive of an act to be later judged in terms of success and failure, but simply as of an act the outcome of which is unknown". (Cage, 1955, p.13 - Tradução nossa).

${ }^{14}$ Ver: https://www.youtube.com/watch?v=HypmW4Yd7SY Acesso em 28 de junho de 2017.

${ }^{15}$ Existem diferentes versões da partitura de 4'33". Há uma, por exemplo, que é constituída por linhas que indicam a duração dos movimentos. Ver: Fetterman, 1996, p. $69-84$
} 
respirações, das tosses, o ruído das poltronas, do ranger do piso de madeira do teatro, do ambiente externo da rua e do trânsito e etc.

Com 4'33", qualquer movimento ou transformação no espaço e no tempo equivalia a uma transformação da identidade acústica. Imerso em um terreno de experimentação, Cage passava a considerar o som como algo existente dentro de um campo aberto de possibilidades (chamado por ele de open field), algo que existe continuamente, sem interrupções e de múltiplas formas. Em sintonia com as White Paintings $^{16}$ (1951) de Rauschenberg ${ }^{17}$, Cage desejava emoldurar a vida real com todos os seus aspectos mutáveis e inconstantes. Nada além do que ali está e, ao mesmo tempo, tudo o que compõe tal vazio e tal silêncio, seja o das telas em branco ou o do espaço onde supostamente "nada" acontece.

Ao explorar o silêncio como território de experimentação, Cage se colocava aberto ao acaso, atendo-se às qualidades que atuavam para produzir um espaço de multiplicidade sonora e, consequentemente, de multiplicidade perceptiva. Joseph (2009) argumenta que nessa época o termo multiplicidade deveria estar carregado de significados distintos para Cage. E, embora a maioria da literatura em torno de Cage tenha se centrado na importância do seu encontro com as filosofias orientais e da Índia, tais como as experiências que teve com Daisetz Suzuki e Ananda K. Coomaraswamy, conexões existentes entre Cage e o filósofo francês Bergson abrem novas perspectivas sobre o pensamento do compositor. Para Joseph (2009), a compreensão de Cage acerca das multiplicidades sonoras e do silêncio pode ser relacionada com as reflexões de Bergson na sua obra $A$ Evolução Criadora ${ }^{18}$.

Em seu livro intitulado Silence (1961), Cage narra a experiência que teve na câmara anecóica da Universidade de Harvard e que desempenhou um papel muito importante para a criação de 4'33". Enquanto esteve nessa câmara anecóica, nesse espaço tecnologicamente isolado, composto por seis paredes feitas de um material especial, Cage nos conta que ouviu dois sons: um agudo e um grave. Cage descreveu os sons que ouviu ao engenheiro responsável que ali estava, que the informou que o som agudo correspondia ao seu sistema nervoso e o grave ao sangue em circulação. Cage, buscando a experiência de estar em silêncio absoluto, percebeu, ao invés disso, os ruídos produzidos pelo seu próprio corpo, fato fundamental para a sua concepção de que não existe espaço ou tempo vazios. A partir dessa experiência, Cage passaria a definir o silêncio não como a total ausência de sons, mas sim a ausência exclusiva de sons intencionais e também a presença de outros sons não desejados (Cage, 1961).

O entendimento de Cage sobre o silêncio, sobre o nada ou sobre o vazio está relacionado a um tipo de atitude perceptiva, a um estado de escuta e atenção, tanto de si, como do outro. E a multiplicidade de acontecimentos, mais ou menos sutis não cessa, colocando o sujeito num fluxo processual de tempo e espaço, onde tudo está em constante transformação. Nesse sentido, 4'33" se revela como uma espécie de "obra meditativa" que coloca em evidência tais questionamentos sobre a percepção do silêncio em relação ao espaço e o tempo. 4'33" pinça um instante e o apresen-

\footnotetext{
${ }^{16}$ Ver: https://www.sfmoma.org/artwork/98.308.A-C Acesso em 28 de junho de 2017.

${ }^{17}$ Segundo Cage (1961) as White Paitings de Rauschenberg foram produzidas antes de 4'33".

${ }^{18}$ Sobre as conexões entre as obras/pensamentos de Cage e a filosofia de Bergson ver: La anarquia del silencio: John Cage y el arte experimental (Joseph, 2009).
} 
ta como duração. E, para Cage, a ideia de duração é entendida como um fenômeno complexo que abrange simultaneidades, processualidades e a multiplicidades de eventos de diferentes naturezas. Além disso, em 4'33" a multiplicidade sonora compreende uma não hierarquização dos sons, deixando de lado ideias composicionais tradicionais, tais como clímax, tema, desenvolvimento, variação e contraste. Não há nenhum sentido de progressão lógica ou algo que exija um tipo específico de continuidade. Há um fluxo, um processo de constante transformação que se manifesta nesta determinada duração de espaço-tempo. Em 4'33", existe uma ideia de "encontrar sons" que pode ser aproximada da ideia de Ready-Made ${ }^{19}$ de Duchamp.

Para Cage, a obra de Duchamp The Bride Stripped Bare by Her Bachelors, Even (The Large Glass) ${ }^{20}$ de 1915-23 era um exemplo de obra paradigmática que produzia uma nova espacialidade pelo emprego da transparência de dois painéis de vidro posicionados um acima do outro, folha e arames de chumbo, óleo e poeira. A criação de The Large Glass é resultante de um estudo meticuloso, envolvendo uma série de anotações, cálculos e experimentações feitas por Duchamp ao longo de anos. Enquanto estavam sendo transportados para serem exibidos em uma exposição no Museu do Brooklyn, os dois painéis foram quebrados. Depois desse acidente, Duchamp reconstruiu a obra, reposicionando cada pedacinho de vidro, sendo, então, o "trincado acidental" do vidro mais um elemento da obra. Em The Large Glass, a espacialidade que convida o espectador a olhar através, compreende, também, o espaço vazio e a ideia de silêncio, que eram muito caras a Cage. Em suas palavras:

Ao olhar para Large Glass, a coisa que eu adoro é que posso focar minha atenção onde quer que eu deseje. A obra me ajuda a borrar a distinção entre arte e vida e produz um tipo de silêncio na própria obra. Não há nada que exija com que eu olhe para um lugar ou outro, na verdade, exige com que eu olhe. Eu posso olhar através dela para o resto do mundo (Cage apud Roth, 1973, p.78) ${ }^{21}$.

Da mesma forma que The Large Glass acionava uma nova perspectiva espacial, 4'33" acionava novas possibilidades sonoras. Há, nas duas obras, um modo não hierárquico de perceber tanto a obra como o entorno. Em 4'33", a não hierarquização da multiplicidade sonora abraça todo som como um evento acústico; de modo similar, The Large Glass e a sua não hierarquização da multiplicidade espacial envolve tudo o que compõe o espaço. Nessas obras, vemos uma maleabilidade sonora e uma maleabilidade espacial, forjadas por perspectivas da escuta e do olhar. Há, por assim dizer, um desejo de desvelar, de tornar visível, de tirar o véu que embaça a percepção do ato criativo daquilo que é ordinário e que inunda a vida cotidiana. Nesse sentido, tanto Cage como Duchamp provocam o espectador no sentido de incluí-lo no ato criativo, afastando-se da ideia de arte como "conteúdo" ou "mensagem" e aproximando-se da ideia de arte como experiência.

\footnotetext{
${ }^{19}$ Trata-se de um conceito empregado inicialmente por Marcel Duchamp (1889-1968) e, em linhas gerais, refere-se a uma apropriação de algo que já está pronto, operando um deslocamento dos sentidos que se depreendem da materialidade e funcionalidade do objeto, ampliando o entendimento do que pode ser definido como arte. A Fonte (1913) e a Roda de bicicleta (1913) são obras de Duchamp definidas como ready-made.

${ }^{20}$ Ver: http://www.philamuseum.org/collections/permanent/54149.html Acesso em 28 de junho de 2017.

21 "Looking at the Large Glass, the thing that I like so much is that I can focus my attention wherever I wish. It helps me to blur the distinction between art and life and produces a kind of silence in the work itself. There is nothing in it that requires me to look in one place or another, in fact, requires me to look at all. I can look through it to the world beyond" (Cage apud Roth, 1973, p.78 - Tradução nossa).
} 
Após a morte de Duchamp, diversos artistas foram incentivados a compor algo em sua homenagem e Cage compôs a sua primeira obra no campo das artes visuais, a Not Wanting To Say Anything About Marcel22(1969). O título foi uma apropriação de um comentário de Jasper Johns, que em conversa com Cage disse que, na verdade, não queria dizer nada sobre Duchamp. Not Wanting To Say Anything About Marcel é composta por oito painéis de acrílico do tipo plexiglass, os quais Cage nomeou de "plexigrams", nos quais, através da técnica de serigrafia, Cage imprimiu imagens e textos. Os painéis foram afixados em uma base de madeira e tudo o que constitui a sua composição foi determinado por operações de acaso usando o l-Ching. Cage usou as quarenta e seis questões com as sessenta e quatro possibilidades de respostas do l-Ching para determinar quais palavras seriam usadas, quais cores, quais ângulos, quais tamanhos e etc. Nessa obra, o espectador é convidado a transitar entre as camadas de imagens sobrepostas, criando e tecendo associações entre cada fragmento que compõe a obra.

Como numa espécie de amálgama entre Cage e Duchamp, em Not Wanting To Say Anything About Marcel, Cage une as suas operações do acaso, a indeterminação gerada pela própria obra com ideia de objetos encontrados de Duchamp (nesta obra, as palavras, cores, camadas sobrepostas de imagens, etc.). Além disso, há também, mais uma vez, uma intersecção entre a ideia de vazio e de silêncio, dada pela transparência do vidro. De novo, o silêncio e o vazio não como a ausência, mas como um desvelar, uma atenção para outras perspectivas mais sutis sobre aquilo que compõe o espaço e o tempo.

\section{Conferência sobre Nada}

As investigações de Cage sobre as operações do acaso, partitura e silêncio consideravam as infinitas possibilidades sonoras que constituem uma obra e estavam impregnadas de ações performativas que também podem ser encontradas em diversas de suas conferências. "Eu não tenho nada a dizer e eu estou dizendo isso e isso é poesia, como eu preciso disso"23 é uma das falas de Cage em sua Lecture on Nothing (Conferência sobre Nada, 1950), publicada em seu livro Silence (1961), que reúne diversos textos e conferências do artista. Neste livro, os textos estão dispostos de forma não exatamente cronológica, revelando atos de fala com seus modos de construção nada convencionais, ou melhor, anticonvencionais. Organizados através de uma clara diferenciação formal e tipográfica, os textos revelam a dimensão transdisciplinar, ou melhor, indisciplinar do trabalho de Cage. Nesse sentido, Silence apresenta diversas pistas sobre as estratégias sistemáticas e subversivas empregadas por Cage para criação de suas obras performativas.

Segundo Robinson (2009), Conferência sobre Nada pode ser considerada a primeira materialização retórica criada por Cage sob a influência do Zen Budismo. Como um texto experimental de poesia, Conferência sobre Nada não lida com a ideia

\footnotetext{
${ }^{22}$ Ver: https://www.pomona.edu/museum/exhibitions/2012/not-wanting-say-anything-about-marcel Acesso em: 28 jun. 2017.

23 "I have nothing to say and I am saying it and that is poetry as I need it" (Cage, 1961, p.109. Tradução nossa). Nesse texto de Cage, a frase não apresenta vírgulas e sim espaços dilatados entre uma parte da frase e outra, além do ponto final após "as I need it".
} 
de compreensão de significados, mas sim com a ideia da experiência de leitura e de escuta como passagem do tempo, atrelada ao sentido de duração. Ao longo do texto, vemos um complexo e meticuloso sistema de organização e disposição espacial de palavras, frases e sinais de pontuação, onde o tempo dilatado evidencia um momento e outro, interrompendo a continuidade linear da leitura/escuta. Tal percepção de temporalidade é dada pelo sentido de duração e também pela ideia de instante pinçado no tempo, quando Cage especifica, por exemplo, o começo de uma determinada seção em relação ao todo do texto.

Em Conferência sobre Nada, temporalidade e duração são também exploradas junto à ideia de repetição, quando Cage, a partir da quarta maior parte da palestra, evidencia que a repetição traz consigo não o "mesmo" novamente, pois, ainda que as frases sejam as mesmas empregadas anteriormente, elas se encontram depois num outro instante de tempo-espaço, configurando-se, portanto, como um outro material ali exposto. Através do emprego da repetição, Cage evidencia um processo sutil de transformações que se dá pela passagem do tempo, em que a ideia de "nada" acontece é derrubada, uma vez que sempre há uma continuidade de acontecimentos, por mais sutis que sejam.

Logo no início de Conferência sobre Nada, Cage nos diz sobre o seu entendimento da noção de continuidade que, para ele, compreende justamente o que acontece na passagem do tempo, com a sua transitoriedade e, também, singularidades e diferenças:

Continuidade hoje, quando necessário, é uma demonstração de desinteresse. Isto é, é uma prova de que o nosso deleite reside em não possuir nada. Cada momento apresenta o que acontece. O quão diferente esse sentido de forma é daquilo que está ligado a memória: temas e temas secundários; a luta entre eles; os seus desenvolvimentos; o clímax; a recapitulação (que é a crença de que alguém pode possuir a sua própria casa). Mas, na verdade, ao contrário do caracol, levamos nossas casas dentro de nós, o que nos permite voar ou ficar, - desfrutar de cada um. Mas tenha atenção ao que é incrivelmente belo, para qualquer momento em que o telefone possa tocar ou o avião descer em um terreno baldio. Um pedaço de corda ou um pôr do sol, possuindo nenhum dos dois, cada um age e a continuidade acontece. Nada mais do que nada pode ser dito. Ouvir ou fazer isso em música não é diferente - apenas é mais simples - do que viver dessa maneira. Mais simples, isto é, para mim, - porque acontece que eu escrevo música (Cage, 1961, p.111) ${ }^{24}$.

Com Conferência sobre $\mathrm{Nada}^{25}$, Cage nos convida a transitar por um complexo processo de desconstrução e recomposição de palavras e frases, criado através de uma série de indagações que surgem ao longo do texto. Vemos uma fala/reflexão filosófica sobre de paradoxos evidenciados por uma composição que contém uma métrica repleta de silêncios. Tais silêncios desestabilizam as convenções e deslocam as expectativas sobre os possíveis modos de leitura, escrita e escuta empregados em

\footnotetext{
${ }^{24} \mathrm{~V}$ "Continuity today, when it is necessary, is a demonstration of disinterestedness. That is, it is a proof that our delight lies in not possessing anything. Each moment presents what happens. How different this form sense is from that which is bound up with memory: themes and secondary themes; their struggle; their development; the climax; the recapitulation (which is the belief that one may own one's own home). But actually, unlike the snail, we carry our homes within us, which enables us to fly or to stay, - to enjoy each. But beware of that which is breathtakingly beautiful, for at any moment the telephone may ring or the airplane come down in a vacant lot. A piece of string or a sunset, possessing neither, each acts and the continuity happens. Nothing more than nothing can be said. Hearing or making this in music is not different - only simpler - than living this way. Simpler, that is, for me, - because it happens that I write music". (Cage, 1961, p.111 Tradução nossa)

${ }^{25}$ Ver: https://www.youtube.com/watch?v=EpNDD0Wyq_w Acesso em 28 de junho de 2017.
} 
uma conferência. Além do que é dado pela leitura e escrita experimental do texto, Cage também preparou seis respostas que seriam dadas para as seis primeiras perguntas que fossem feitas após a leitura do texto, o que revela mais um aspecto da dimensão performativa de seus projetos e das suas investigações acerca das operações do acaso.

Ao longo de sua trajetória, Cage explorou as especificidades do som e suas inúmeras variações, desenvolvendo um entendimento e uma apropriação particular das noções de acaso, de partitura e de silêncio. Suas obras, impregnadas por seus atos performativos, revelam o interesse de Cage pela ação da música. Cage defendia a multiplicidade sonora e a força expressiva contida em cada som, distante de qualquer sentido figurativo ou representativo, não precisando se apoiar em nada que estivesse fora do seu domínio ou do seu próprio meio para "justificar" a sua existência. Cage, por exemplo, nos diz sobre o som sendo "ele mesmo", nada mais do que isso:

Quando escuto aquilo que chamamos de música, me parece que alguém está falando, e falando sobre seus sentimentos ou sobre suas ideias de relacionamentos. Mas quando eu escuto o trânsito, o som do trânsito aqui na Sexta Avenida, por exemplo, eu não tenho a sensação de que alguém está falando. Tenho a sensação de que o som está atuando. E eu adoro a atividade do som. O que ele faz é ficar mais forte ou suave, mais agudo ou grave, mais longo ou curto. Ele faz todas essas coisas com as quais fico completamente satisfeito. Não preciso do som falando comigo. Não vemos muita diferença entre tempo e espaço. Não sabemos onde um começa e o outro para. Então, há muito da arte que pensamos estar no tempo, e muito que pensamos estar no espaço. Marcel Duchamp por exemplo, começou a pensar no tempo, quero dizer, pensando na música não como uma arte do tempo, mas sim uma arte do espaço. E ele compôs uma peça chamada Sculpture Musicale, que significa diferentes sons, vindo de locais diferentes, duradouros, produzindo uma escultura que é sonora e que permanece. As pessoas esperam que o ouvir seja mais que ouvir. Então, às vezes, elas falam de uma escuta interna ou do significado do som. Quando eu falo sobre música, finalmente chega até a mente das pessoas que eu estou falando de som, que não tem significado. E não é interno, mas é somente externo. E elas falam, essas pessoas que entendem isso, finalmente falam: 'Você quer dizer que são só sons?' Pensando que algo que é apenas um som, é algo inútil. Enquanto eu amo sons, exatamente como eles são. $\mathbf{E}$ não tenho a necessidade que eles sejam algo além do que eles são. Não quero que eles sejam psicológicos, não quero um som que finja que é um balde, ou que é o presidente, ou que está apaixonado por outro som. Eu só quero que seja um som (Cage, 1992, s/p. Grifos nossos) ${ }^{26}$.

Cage, na citação acima, nos fala da ação do som, do som sendo ele mesmo e não algo que representa alguma outra coisa e, mais uma vez, cita o trabalho de Duchamp. A partir de Duchamp, Cage menciona uma espécie de indistinção entre tem-

\footnotetext{
26 "When I hear what we call music, it seems to me that someone is talking, and talking about his feelings, or about his ideas of relationships. But when I hear traffic, the sound of traffic, here on 6th avenue for instance, I don't have the feeling that anyone is talking. I have the feeling that sound is acting. And I love the activity of sound. What it does is it gets louder and quieter, and it gets higher and lower, and it gets longer and shorter. It does all those things. I am completely satisfied with that. I don't need sound to talk to me. We don't see much difference between time and space. We don't know where one begins and the other stops. So that most of the arts we think of as being in time, and most of the arts we think of being in space. Marcel Duchamp, for instance, began thinking of music as being not a time art, but a space art. And he made a piece called "Sculpture Musicale," which means: different sounds coming from different places and lasting, producing a sculpture which is sonorous and which remains. People expect listening to be more than listening. And so they sometimes speak of inner listening, or the meaning of sound. When I talk about music, it finally comes to people's minds that I'm talking about sound that doesn't mean anything, that is not inner, but is just outer. And they, these people who understand that, finally say: "you mean it's just sounds?" - thinking for something to be just being a sound is to be useless. Whereas I love sounds, just as they are. And I have no need for them to be anything more than what they are. I don't want them to be psychological, I don't want sound to pretend it's a bucket or that it is president or that it is in love with another sound. I just want it to be a sound". Fala de John Cage no documentário Listening (Sebestik, 1992 - Tradução nossa).
} 
po e espaço, onde a música passa a ser uma arte não apenas do tempo, mas também do espaço.

Diante das obras experimentais de Cage e também de Duchamp, o espectador é convidado a participar do ato criativo, experimentando outras qualidades de percepção temporal e espacial. Nada é dado como certo, fixo, fechado ou acabado. Os sons, as formas, as cores são o que são, no sentido que não representam algo além de suas propriedades sonoras e visuais. Tanto Cage como Duchamp estavam interessados menos no "entendimento" ou na "mensagem" da obra de arte e mais na arte como experiência. Na visão de Cage:

[Muitas pessoas] Têm grande dificuldade em prestar atenção a algo que eles não entendem. Acho que a divisão está entre compreender e experimentar, e muitas pessoas pensam que a arte tem a ver com o entendimento; mas não tem. Tem a ver com a experiência; e se você entende alguma coisa, então você vai embora, uma vez que você compreende, porque você não quer a experiência. Você não quer ser irritado (Cage apud Kostelanetz, 1987, p.115) ${ }^{27}$.

Cage, ao defender a arte como experiência, considerava que tanto obra como espectador sofrem a ação do tempo e do espaço e, aquilo que a obra é, aciona ou faz acontecer (podendo ser, acionar e fazer acontecer múltiplas e diversas coisas), dá-se por um ato de desvelar ou desdobrar o potencial de criação que está tanto na obra como no espectador. Cage acreditava na força do acontecimento e, nesse sentido, criava suas obras como situações que, de alguma forma, despertassem a atenção e a percepção do espectador para uma determinada experiência estética que pode se dar tanto na arte como na vida.

\section{O legado indisciplinar de John Cage}

Como foi possível observar até aqui, as proposições de Cage envolvendo a criação do piano preparado, o trabalho com as noções de operações do acaso, partitura e de silêncio foram marcadas por sua atitude questionadora, inventiva e subversiva. Cage não apenas desafiou os modos de composição vigentes em sua época, como também investiu em uma intensa integração entre os diferentes campos de conhecimento. As ações cageanas eram transdisciplinares por natureza, pois não valorizaram um saber sobre o outro e pareciam buscar um constante entrelaçamento entre diferentes saberes e, sobretudo, entre arte e vida. Cage borrava as fronteiras entre os diversos campos de conhecimento e seus atos pareciam estar impregnados por um desejo de desvio das convenções estabelecidas. Nesse sentido, além de transdisciplinares, as proposições de Cage eram também indisciplinares, pois propunham desvios dos padrões e normas vigentes, reconfigurando, inclusive, os limites entre uma disciplina e outra.

E as proposições de Cage contaminaram diversos artistas ao longo do século XX. No campo das Artes da Cena, mais especificamente da dança, além da célebre

\footnotetext{
27 "Have great difficulty paying attention to something they don't understand. I think that the division is between understanding and experiencing, and many people think that art has to do with understanding; but it doesn't. It has to do with experience; and if you understand something, then you walk once you get the point because you don't want the experience. You don't want to be irritated" (Cage apud Kostelanetz, 1987, p.115 - Tradução nossa).
} 
parceria desenvolvida com Cunningham, Cage também foi fundamental para o nascimento do efervescente coletivo Judson Dance Theater ${ }^{28}$, cujos traços performativos ainda ressoam na dança contemporânea atual.

Se para Cage todo som poderia ser música, para os artistas do Judson, todo e qualquer movimento poderia ser dança. Embora os trabalhos de Cunningham em sua parceria com Cage tivessem sido criados dentro de uma prática de colaboração não hierárquica e suas noções composicionais expandido as possibilidades de criação em dança, o vocabulário de movimento ainda requeria dançarinos com um forte treinamento em dança moderna e balé clássico. Já os dançarinos do Judson, por sua vez, apropriaram-se com radicalidade do legado indisciplinar de Cage, questionando não apenas o que poderia ser emoldurado como dança, mas também o que seria um treinamento em dança e quem poderia dançar.

Nesse período dos anos de 1960, o estúdio de Cage e Cunningham era, em muitos sentidos, um lugar cercado por diversas experimentações inovadoras. $O$ grupo de teatro experimental Living Theater, por exemplo, ocupava o andar de cima do mesmo prédio. E lá, Robert Dunn ofereceu aulas que nutriram o terreno a partir do qual o Judson Dance Theater surgiu. Cage pediu à Dunn que ministrasse aulas de composição no estúdio de Cunningham. E Dunn, que tinha sido aluno de Cage na aula de Composição Experimental na New School for Social Research, passou a explorar nessas aulas ideias como indeterminação, acaso, tarefas e partituras.

Ao falar sobre o processo de criação de Street Dance (1964), Lucinda Childs, que fez parte do coletivo Judson, nos dá uma ideia sobre como eram as aulas de Dunn ${ }^{29}$. Childs nos conta que Dunn havia dado uma limitação aos alunos: compor uma dança de seis minutos. Então, Childs decidiu que poderia sair do estúdio, deixando algo para trás: uma fita pré-gravada dizendo onde ela estava indo. Childs escolheu dançar do outro lado da rua e, de um modo extremamente preciso, marcou o tempo de seu trajeto, saindo do estúdio e executando na rua as ações que pretendia. Depois, tendo a duração exata de cada ação, Childs gravou um áudio com a descrição/instrução de tudo o que acontecia. Enquanto ela e outra dançarina ocupavam a rua, o público (seus colegas de aula) ouvia, dentro do estúdio, instruções específicas para olhar pela janela em direção à rua, notando certas ações. Enquanto dançavam, Childs e outra dançarina tinham registrado em seus corpos o tempo de tudo, então, elas chegaram na rua exatamente ao mesmo tempo em que a voz de Childs surgiu na gravação, dizendo onde elas estavam e o quê estavam fazendo. Com Street Dance, Childs guiava o público que estava dentro do estúdio e, provavelmente, também os transeuntes,

\footnotetext{
${ }^{28} \mathrm{Em}$ 1962, em Nova York, dançarinos, artistas visuais, músicos se apresentaram no salão da igreja Judson Memorial Church, em Greenwich Village, dando origem ao Judson Dance Theater. Durante a sua existência (1962-1964), esse coletivo de artistas verticalizou a ideia de que todo e qualquer movimento poderia ser dança, dando origem ao surgimento da dança pós-moderna. Dentre os artistas que integraram o grupo estão: Judith Dunn, Robert Dunn, Ruth Emerson, Alex Hay, Deborah Hay, Fred Herko, David Gordon, Gretchen MacLane, John Herbert McDowell, Robert Morris, Steve Paxton, Rudy Perez, Yvonne Rainer, Robert Rauschenberg, Carol Scothorn, Elaine Summers, Jennifer Tipton, Trisha Brown, Remy Charlip, Lucinda Childs, Carolee Sheneemann, David Gordon, Sally Gross, Elizabeth Keen, Aileen Passloff, Albert Reid, Arlene Rothlein, Meridith Monk, dentre outros. Ver: ALMEIDA, Karina Campos de. Entre-territórios: a dança como catalisadora de diferentes noções de composição. Tese (doutorado) - Universidade Estadual de Campinas, Instituto de Artes, Campinas, SP. Endereços eletrônicos de algumas obras:

https://www.youtube.com/watch?v=UEZFj0xPQMw

https://www.youtube.com/watch?v=ukbGiRyB8n4\&t=21s

https://www.youtube.com/watch?v=D6AK9TI3-LU Acesso em: 28 jun. 2017

${ }^{29}$ Ver: The uncut sessions, Lucinda Childs, part 1 (Ipiotis; Bush, 1991).
} 
para perceberem a cidade e o contexto urbano por meio de um sentido cinestésico. Nessa obra, é possível notar como Childs explorou noções propagadas por Cage e abordadas por Dunn nessas aulas de composição, tais como indeterminação, acaso e partitura/roteiro/tarefa. Ao compor uma coreografia a partir da tarefa "criar uma dança de seis minutos", Childs elaborou um roteiro que compreendia não apenas a sincronia e a precisão entre as ações e o áudio, mas também a imprevisibilidade trazida pelo fluxo urbano.

Como resultado das aulas de Dunn foi organizado o evento A Concert of Dance (1962), que durou mais de três horas. De 1962 a 1964, os artistas do Judson mostraram seus trabalhos em dezesseis programas coletivos. "Imprevisível" e "não convencional"30 eram alguns dos adjetivos mais usados pela crítica e pelo público para descrever as danças do Judson. Dentre muitos trabalhos interdisciplinares e transgressores ligados a este coletivo e que exploraram materiais não convencionais, vemos, por exemplo, o violento Meat Joy (1964), de Carolee Schneemann, que envolvia pessoas nuas, peixe, frango e salsicha, e, também, o Concert\#13, com o cenário de Charles Ross, feito de uma enorme pilha de cadeiras e uma grande estrutura de balanço no meio do santuário.

Em seu artigo Lookink myself in the mouth (1981), Yvonne Rainer, uma das figuras mais celebradas do Judson, nos fala da influência de Cage sobre os artistas de sua geração:

Quem sou eu e qual é a minha dívida com John Cage? Minhas primeiras danças (1960-62) empregavam procedimentos do acaso ou improvisação para determinar sequências de frases de movimento coreografadas. Naquela época, para alguns de nós que performavam na Judson Church em Nova York, repetição, sequenciamento indeterminado, sequências dadas por métodos aleatórios e movimentos ordinários/ não transformados eram um tapa na cara da antiga ordem [...] Uma resposta frequente para a perplexidade dos não iniciados era 'Por que não?' (Rainer, 1981, p.67) ${ }^{31}$.

Repetição, acumulação, fragmentação, montagem, colagem, justaposições radicais, estruturas/ações guiadas por tarefas, operações do acaso, movimentos cotidianos, desconstrução da narrativa linear e de causa-efeito são algumas das noções composicionais que se tornaram recorrentes nas práticas de criação dos artistas do Judson. Imbuídos pelo espírito revolucionário daquela época, tais artistas posicionavam-se contra as instituições oficias vigentes, alinhando-se ao movimento contracultural que surgia a partir de 1960. Nesse período, o Judson se tornou catalisador de muitas ideias que também estavam alimentando os Happenings e a Performance Art. Nesse contexto de experimentação, as fronteiras entre as diversas formas de expressão artísticas foram borradas, não permitindo mais se falar em modelos e categoria

\footnotetext{
${ }^{30}$ Por exemplo, Allen Hughes em sua crítica publicada em 7 de julho de 1962 no jornal The New York Times afirmou: "uninstructed followers of the conventional would more than likely have found the evening an exercise in madness, but it wasn't. Perhaps it would have been more accurate to call it a concert of 'movement' rather than of 'dance,' but by any name it was a thought-provoking venture. Its fifteen numbers were organized by means of "indeterminacy, improvisation, and spontaneous determination," to quote the choreographers themselves, and it will therefore never happen in precisely the same way again". Acessado na New York University Fales Library - Downtown Collection.

31 "Who am I and what is my debt to John Cage? My early dances (1960-62) employed chance procedures or improvisation to determine sequences of choreographed movement phrases. At that point, for some of us who performed at Judson Church in New York City, repetition, indeterminate sequencing, sequence arrived by aleatory methods, and ordinary/untransformed movement were a slap-in-the-face to the old order [...]. A frequent response to the bafflement of uninitiated was 'Why not'?" (Rainer, 1981, p.67-Tradução nossa).
} 
tácitas.

Por exemplo, temos a obra Trio A - The Mind Is a Muscle, Part 132 (1966), de Yvonne Rainer, que se tornou um marco desse período. Nessa obra, Rainer excluiu noções composicionais tradicionais como tema, variação, repetição, clímax, contraste, desenvolvimento lógico, explorando um tipo de performance supostamente "neutra", uma atividade orientada pela ideia de tarefa, na qual cada parte era igual, sem destaque ou valorização de uma sobre a outra. Além disso, na estreia dessa obra, Rainer, Steve Paxton e David Gordon dançavam, enquanto Alex Hay arremessava inúmeras tábuas de madeira, uma por vez, do mezanino do segundo andar da igreja (Rainer, 2013, p.269).

Outra artista emblemática que integrou o Judson foi Trisha Brown. As obras que desenvolveu no período de 1966 a 1979 carregavam todo o experimentalismo deflagrado pelo coletivo do Judson, tornando-se referência desse período da dança pós-moderna. A obra Man Walking Down the Side of the Building ${ }^{33}$ (1970) se enquadra dentro das "peças de equipamento" de Trisha, tendo como ação central um homem que, pendurado por uma corda de equipamento de alpinismo, caminha pelo lado de fora de um prédio, com seu corpo inclinado em noventa graus em relação à parede. Utilizando este equipamento, o peso do corpo é sustentado, criando a imagem surreal de um homem caminhando lentamente pela fachada de um prédio, como se ele pudesse resistir à força da gravidade.

Além de referências provenientes de Anna Halprin (com suas danças tarefas, improvisação e utilização do ambiente externo) e de Simone Forti (com suas danças focadas na exploração da gravidade, como Slant Board [1961]), é possível reconhecer em Man Walking a influência de Cage. Se em 4'33" Cage emoldurou um tempo de duração específico e evidenciou os sons contidos nesse espaço "de silêncio", em Man Walking Trisha determinou como duração da obra o comprimento da parede, evidenciando nesse tempo-espaço específico um modo irreverente de caminhar, guiando a percepção do público para a dança que está contida nessa ação e também na vida cotidiana.

Cientes de toda a complexidade existente em torno das obras de Cage, expusemos neste artigo em que medida suas ações experimentais abriram caminho para práticas vanguardistas que marcaram a segunda metade do século XX. Como vimos, no campo das Artes da Cena e mais especificamente na área da Dança, além da parceria desenvolvida com Cunningham, Cage nutriu o terreno de onde surgiram experimentações como as do Judson Dance Theater que mudaram certos paradigmas até então vigentes. Diante de sua prolífica trajetória, Cage deixou um legado não só transdisciplinar como indisciplinar, na medida em que não só atravessou todas as artes, como borrou suas fronteiras, despertando nossa atenção e sensibilidade para possibilidades de invenções, subversões e composições cotidianas.

\footnotetext{
${ }^{32}$ Ver: https://www.youtube.com/watch?v=Em_-A44HNzc Acesso em: 28 jun. 2017.

${ }^{33}$ Ver: https://www.youtube.com/watch?v=MpGsEOR9db0 Acesso em: jun. 2017.
} 


\section{Referências}

BERGSON, Henri. A evolução criadora. Trad. Adolfo Casais Monteiro. Estudo introdutivo de Jean Guitton. Ilustrações de Kischka. Delta: Rio de Janeiro, 1964.

CAGE, John. Silence. Middletown: Wesleyan University Press, 1961.

Empty Words. Writings '73 - '78. Middletown: Wesleyan University Press, 1981.

A Year From Monday: New Lectures and Writings by John Cage. Middletown: Wesleyan University Press, 1967.

CAVRELL, Holly Elizabeth. Dando Corpo à História. Curitiba: Prismas, 2015.

FETTERMAN, William. John Cage's Theatre Pieces: Notations and Performances. Amsterdam: Harwood Academic Publishers, 1996.

JOSEPH, Branden W. "Azar, indeterminación, multiplicidade". In: ROBINSON, Julia (ed.). La anarquia del silencio: John y el arte experimental. Barcelona: MACBA, 2009, p.210-238.

KOSTELANETZ, Richard. Conversing with Cage. New York: Limelight Editions, 1987.

PRITCHETT, James. "Lo que el silencio enseñó a John Cage: la historia de 4'33". In: ROBINSON, Julia (ed.). La anarquia del silencio: John y el arte experimental. Barcelona: MACBA, 2009, p.166-177.

RAINER, Yvonne. "Looking myself in the mouth". In: OCTOBER, Vol. 17, The New Talkies, 1981, p. 65-76.

Feelings are Facts, First MIT Press paperback edition, 2013.

ROBINSON, Julia (ed.). La anarquia del silencio: John y el arte experimental. Barcelona: MACBA, 2009.

"John Cage y la 'investidura': emascular el sistema". In: ROBINSON, Julia (ed.). La anarquia del silencio: John y el arte experimental. Barcelona, MACBA, 2009, p.55-111.

ROTH, Moira; ROTH William. "John Cage on Marcel Duchamp". In: Art in America 61, n으, Nov-Dec, 1973, p.71-79.

SEBESTIK, Miroslav; BIDOU, Jacques. Listening (vídeo documentário), França, 120', 1992. 
ZULLO, Douglas Richard. Getting off the Ground: Wassily Kandinsky, John Cage, and the otherworldly qualities of the everyday world. Thesis, The Ohio State University, 1997.

Recebido em: 25/11/2016 Aprovado em: 14/06/2017 